\title{
Effect of osteoprotegerin and osteoprotegerin ligand on osteoclast formation by arthroplasty membrane derived macrophages
}

\author{
I Itonaga, A Sabokbar, D W Murray, N A Athanasou
}

\begin{abstract}
Objective-Osteoprotegerin ligand (OPGL) is a newly discovered molecule, which is expressed by osteoblasts/bone stromal cells. This ligand and M-CSF are now known to be essential for osteoclast differentiation from marrow and circulating precursors. This study examined whether OPGL and its soluble receptor osteoprotegerin (OPG), influenced osteoclast formation from human arthroplasty derived macrophages, to determine if the effects of OPGL and OPG on these cells could contribute to the osteolysis of aseptic loos-
\end{abstract} ening.

Methods-OPGL ( \pm dexamethasone/MCSF) was added to cultures of macrophages isolated from the pseudomembrane of loosened hip arthroplasties incubated on glass coverslips and dentine slices. OPG was added to cocultures of arthroplasty derived macrophages and UMR106 osteoblast-like cells. Osteoclast differentiation in long term cultures was assessed by expression of macrophage (CD14) and osteoclast markers (tartrate resistant acid phosphatase (TRAP), vitronectin receptor (VNR) and lacunar resorption).

Results-In the absence of osteoblastic cells, the addition of OPGL alone was sufficient to induce differentiation of macrophages $\left(\mathrm{CD}_{14}^{+}, \mathrm{TRAP}^{-}, \mathrm{VNR}^{-}\right)$into $\mathrm{TRAP}^{+}$ and $\mathrm{VNR}^{+}$multinucleated cells, capable of extensive lacunar resorption. OPG was found to inhibit osteoclast formation by arthroplasty macrophages in a dose dependent manner. OPG (100 ng/ml) more than halved the formation of TRAP $^{+}$and $\mathrm{VNR}^{+}$cells and the extent of lacunar resorption in co-cultures of UMR106 cells and arthroplasty macrophages.

Conclusions-This study has shown that macrophages, isolated from the pseudomembrane surrounding loose arthroplasty components, are capable of differentiating into osteoclastic bone resorbing cells and that OPGL is required for this to occur. OPG inhibits this process, most probably by interrupting the cell-cell interaction between osteoblasts and mononuclear phagocyte osteoclast precursors present in the pseudomembrane.

(Ann Rheum Dis 2000;59:26-31)
Aseptic loosening is the commonest cause of late failure of cemented and uncemented joint replacements. Loosening of implant components is thought to occur in over $10 \%$ of cases within 20 years of the initial hip replacement. A heavy foreign body macrophage response to polymeric and metallic wear particle is found in the pseudocapsule and pseudomembrane surrounding the implant. ${ }^{1-3}$ Surrounding this macrophage rich infiltrate there is considerable periprosthetic osteolysis. ${ }^{45}$ The cellular mechanisms underlying this pathological bone resorption and the manner in which the heavy foreign body macrophage infiltrate in periprosthetic tissues contributes to this osteolysis remain uncertain.

Cells in the implant pseudomembrane are known to produce humoral factors, including cytokines/growth factors and prostaglandins, which activate osteoblasts to stimulate osteoclastic bone resorption. ${ }^{6-10}$ Another means whereby macrophages contribute directly to the osteolysis of aseptic loosening is by differentiation of these cells into bone resorbing osteoclasts. It has been shown that mouse monocytes and tissue macrophages, including inflammatory foreign body macrophages derived from granulomas formed in response to subcutaneously implanted metallic and polymeric particles, are capable of differentiating into osteoclasts. ${ }^{11-13}$ Coculture with osteoblastic cells in the presence of 1,25 dihydroxyvita$\min \mathrm{D}_{3}\left[1,25(\mathrm{OH})_{2} \mathrm{D}_{3}\right]$ is required for this to occur. We have also recently shown that human wear particle associated macrophages isolated directly from periprosthetic tissues surrounding loosened implants can differentiate into multinucleated cells showing all the functional and cytochemical characteristics of osteoclasts. ${ }^{14}$ In contrast with osteoclast formation from human monocyte and other inflammatory macrophage populations in vitro, which requires the addition of macrophage-colony stimulating factor (M$\mathrm{CSF})$ as well as $1,25(\mathrm{OH})_{2} \mathrm{D}_{3}$, arthroplasty macrophage-osteoclast differentiation does not require exogenous $\mathrm{M}$-CSF. In the context of the heavy macrophage response to wear particles, macrophage-osteoclast differentiation may thus, represent an important cellular mechanism whereby osteolysis is effected in aseptic loosening in periprosthetic tissues.

Osteoclast differentiation from mononuclear phagocyte precursors is known to require the cooperation of osteoblasts/bone stromal cells. ${ }^{15}$ It has recently been shown that these cells express an osteoclast differentiation factor, also 
termed osteoprotegerin ligand (OPGL), which induces osteoclast formation from marrow and circulating precursors. ${ }^{16}{ }^{17}$ OPGL is a member of the tumour necrosis factor (TNF) ligand superfamily and interacts with an osteoclastogenesis inhibitory factor or osteoprotegerin (OPG), a secreted member of the TNF receptor family. ${ }^{18-20}$ In this study, we show that OPGL plays a major part in arthroplasty macrophage-osteoclast differentiation and that this process can be inhibited by OPG.

\section{Methods}

MATERIALS

For all incubations $\alpha$ minimal essential medium (MEM) (Gibco, UK) was supplemented with $100 \mathrm{IU} / \mathrm{ml}$ penicillin, $10 \mu \mathrm{g} / \mathrm{ml}$ streptomycin, $10 \mathrm{mM}$ L-glutamine (Gibco, UK) and $10 \%$ fetal calf serum (FCS) (Gibco, UK) (MEM/FCS). Collagenase Type I, $0.25 \%$ trypsin solution and dexamethasone were purchased from Sigma Chemicals (UK). Recombinant human macrophage colony stimulating factor (M-CSF) was obtained from R \& D Systems (UK). 1,25 dihydroxyvitamin $\mathrm{D}_{3}\left[1,25(\mathrm{OH})_{2} \mathrm{D}_{3}\right]$ was purchased from Solvay Duphar (Netherlands). OPG and OPGL were kindly provided by Dr D Lacey, Amgen (Thousand Oaks, CA, USA). All incubations were carried out at $37^{\circ} \mathrm{C}$ in $5 \% \mathrm{CO}_{2}$.

ISOLATION OF CELLS FROM THE ARTHROPLASTY PSEUDOMEMBRANE

Specimens of the femoral and acetabular pseudomembrane were obtained fresh from six patients (three women and three men; age range 48 to 85 years), undergoing revision arthroplasty for aseptic loosening of the hip who were initially diagnosed to be suffering from primary osteoarthritis. The cell suspension derived from these tissues was prepared as described previously. ${ }^{14}$ Briefly, tissue specimens were washed thoroughly with phosphate buffered saline (PBS) before being cut into small fragments and digested in MEM containing 1 $\mathrm{mg} / \mathrm{ml}$ collagenase Type I for 30 minutes at $37^{\circ} \mathrm{C}$; this was followed by a further one hour incubation in $0.25 \%$ trypsin. The digested tissue was filtered with a $70 \mu \mathrm{m}$ cell strainer (Falcon, UK) and the filtrate centrifuged at $800 \mathrm{~g}$ for 10 minutes. The cell pellet was resuspended in MEM/FCS and the number of leucocytes determined in a haemocytometer after lysis of red blood cells using a 5\% (v/v) acetic acid solution.

CULTURE OF ARTHROPLASTY DERIVED

MACROPHAGES: THE EFFECT OF OPGL ON

MACROPHAGE-OSTEOCLAST DIFFERENTIATION

The effect of OPGL on macrophage-osteoclast differentiation was studied in four of the six specimens. The cell suspension obtained from arthroplasty tissues $\left(1 \times 10^{5}\right.$ cells/well $)$ was added to 96 well tissue culture plates containing dentine slices ( $4 \mathrm{~mm}$ diameter) and glass coverslips (6 $\mathrm{mm}$ diameter). After incubation for two hours, dentine slices and coverslips were removed from the wells, washed vigorously in MEM/FCS to remove non-adherent cells, and then placed in $16 \mathrm{~mm}$ wells of a 24 well tissue culture plate containing $1 \mathrm{ml}$ $\mathrm{MEM} / \mathrm{FCS}$, both in the presence and absence of one or more of the following factors; 30 $\mathrm{ng} / \mathrm{ml}$ OPGL, $25 \mathrm{ng} / \mathrm{ml} \mathrm{M-CSF}$, and $10^{-8} \mathrm{M}$ dexamethasone. These cultures were incubated for 1, 4, 7, 11 and 14 days and the culture medium containing these factors was replenished every three days. The extent of osteoclast formation was assessed in terms of the expression of cytochemical and functional markers of the osteoclast phenotype (see below).

THE EFFECT OF OPG ON OSTEOCLAST FORMATION IN COCULTURES OF OSTEOBLASTS (UMR106 CELLS) AND ARTHROPLASTY DERIVED MACROPHAGES Osteoclast formation is known to occur when arthroplasty derived macrophages are cocultured with osteoblastic cells in the presence of $1,25(\mathrm{OH})_{2} \mathrm{D}_{3} \cdot{ }^{14}$ The effect of OPG on osteoclast formation was assessed in this coculture system in five of the six specimens. Twenty four hours before the isolation of cells from arthroplasty tissues, $2 \times 10^{4}$ rat osteoblastic UMR106 cells (kindly provided by Professor T J Martin, Melbourne, Australia) $)^{21}$ were added to 96 well tissue culture plates containing dentine slices and glass coverslips. The cell suspension obtained from arthroplasty tissues was added to each well $\left(1 \times 10^{5}\right.$ cells/well $)$ and incubated for two hours, after which time all dentine slices and coverslips were removed from the wells, washed vigorously in MEM/FCS to remove non-adherent cells, and then placed in $16 \mathrm{~mm}$ wells of a 24 well tissue culture plate containing $1 \mathrm{ml}$ of $\mathrm{MEM} / \mathrm{FCS}$ supplemented with OPG $(0,10,50,100 \mathrm{ng} / \mathrm{ml}), 1,25(\mathrm{OH})_{2} \mathrm{D}_{3}$ $\left(10^{-7} \mathrm{M}\right)$ and dexamethasone $\left(10^{-8} \mathrm{M}\right)$. These cocultures were incubated for 1,7 and 14 days and the culture medium containing these factors was replenished every three days. The extent of osteoclast formation was assessed in terms of the expression of cytochemical and functional markers of the osteoclast phenotype (see below).

\section{CYTOCHEMICAL CHARACTERISATION OF} CULTURED CELLS

After 1, 4, 7, 11 and 14 days incubation, cell cultures on coverslips (incubated both in the presence and absence of UMR106 cells) were characterised histochemically for the expression of tartrate resistant acid phosphatase $(\text { TRAP })^{22}$ using a commercially available kit (Sigma, UK). Cell cultures on coverslips were also stained immunohistochemically by an indirect immunoperoxidase technique ${ }^{23}$ with the monoclonal antibodies 23C6 (a gift of Professor $\mathrm{M}$ A Horton, London, UK $)^{24}$ and GRS $1^{25}$; these antibodies are directed respectively against CD51, the vitronectin receptor (VNR), an osteoclast associated antigen, and CD14, a macrophage associated antigen that is not expressed by osteoclasts. ${ }^{26}$

FUNCTIONAL EVIDENCE OF OSTEOCLAST DIFFERENTIATION: DETECTION OF LACUNAR RESORPTION

Functional evidence of osteoclast formation was determined by a lacunar resorption assay system using cell cultures on dentine slices. 
This provides a smooth surfaced mineralised substrate for the assessment of lacunar resorption. ${ }^{27}$ After cells had been cultured on dentine slices for $1,4,7,11$ and 14 days, the slices were removed from the wells, rinsed in
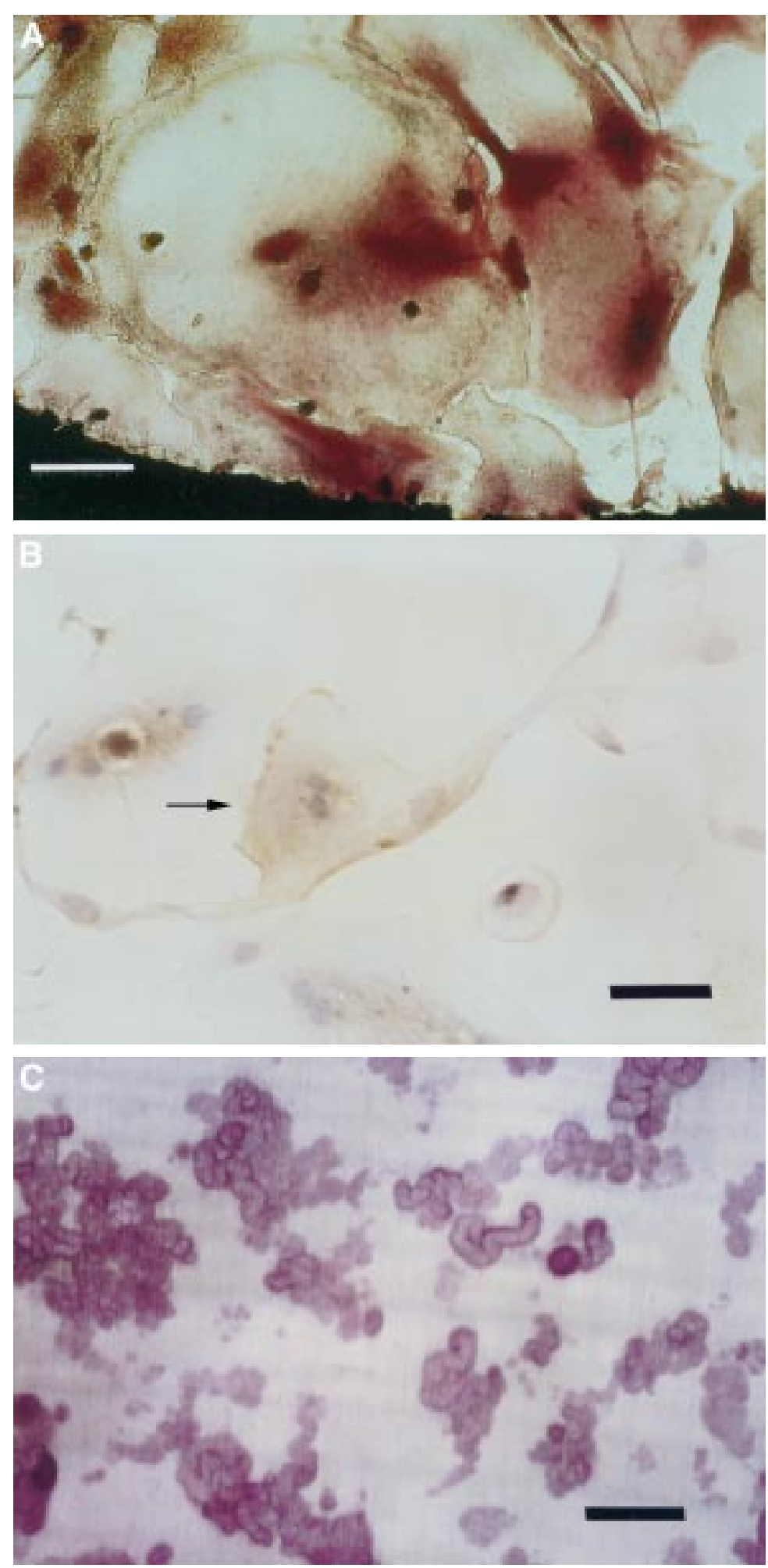

Figure 1 Arthroplasty derived macrophage cultures on coverslips and dentine slices in the presence of OPGL (30 ng/ml) for 14 days showing: (A) numerous TRAP cells on a glass coverslip (stained with Fast Garnet GBC salt; counterstained with haematoxylin, bar $=50$ $\mu m$ ). (B) VNR multinucleated cells on a glass coverslip (one arrowed) (indirect immunoperoxidase staining; counterstained with haematoxylin, bar $=50 \mu \mathrm{m}) .(C)$ Extensive lacunar resorption pit formation on a dentine slice (toluidine blue staining, bar = $250 \mu \mathrm{m})$.
PBS, and placed in $0.25 \%$ trypsin for $15 \mathrm{~min}$ utes; dentine slices were then washed vigorously in distilled water and left overnight in $0.25 \mathrm{M}$ ammonium hydroxide. In this way all cells are completely removed from the dentine slice, permitting examination of the dentine surface for evidence of lacunar resorption. The slices were then washed in distilled water, stained with $0.5 \%(\mathrm{w} / \mathrm{v})$ toluidine blue, and examined by light microscopy.

The extent of lacunar resorption on dentine slices was determined by counting the number of resorption pits. Each experiment was repeated at least three times and for each treatment the data were expressed as the mean number of lacunar pits formed on three dentine slices. The effect of adding mediators was quantified by calculating the percentage change in the mean number of pits. Statistical significance of the effect of OPG and OPGL on lacunar resorption changes was assessed using Student's $t$ test.

\section{Results}

OPGL STUDIES

Effect of OPGL on arthroplasty

macrophage-osteoclast differentiation

Adherent cells isolated from the arthroplasty pseudomembrane, incubated for 24 hours on glass coverslips, both in the presence and absence of $30 \mathrm{ng} / \mathrm{ml}$ OPGL, showed strong expression of CD14, a macrophage cell surface antigen that is known not to be present on osteoclasts. These cells were largely negative for the osteoclast markers, TRAP and VNR. Lacunar resorption was not seen in 24 hour cultures on dentine slices.

After 14 days incubation, the addition of 30 $\mathrm{ng} / \mathrm{ml}$ OPGL to arthroplasty macrophage cultures was found to be sufficient to induce macrophage-osteoclast differentiation in the absence of osteoblastic cells and human $\mathrm{M}-\mathrm{CSF}$. In the presence of $30 \mathrm{ng} / \mathrm{ml}$ OPGL alone, many $\mathrm{TRAP}^{+}$and $\mathrm{VNR}^{+}$mononuclear and multinucleated cells were observed on the coverslips, and numerous lacunar resorption pits were found on the dentine slices (fig 1). The mean number of pits on each dentine slice was 32. In the absence of OPGL, pits were not formed on dentine slices. Macrophage cell cultures incubated for 14 days in the presence of OPGL and M-CSF, or OPGL and dexamethasone, showed a small but not significant increase in the number of resorption pits formed on dentine slices compared with cell cultures incubated with OPGL alone. However, when OPGL, M-CSF and dexamethasone were added together to cell cultures, there was a marked increase $(70 \%)$ in the extent of lacunar resorption compared with cultures incubated with OPGL alone $(\mathrm{p}=0.025)$ (fig 2$)$.

The time course of arthroplasty

macrophage-osteoclast differentiation in the presence of OPGL

As noted above, 24 hours cultures on glass coverslips and dentine slices in the presence of OPGL (30 ng/ml), both in the presence and absence of $25 \mathrm{ng} / \mathrm{ml} \mathrm{M}$-CSF and $10^{-8} \mathrm{M}$ dexamethasone, were negative for TRAP and 


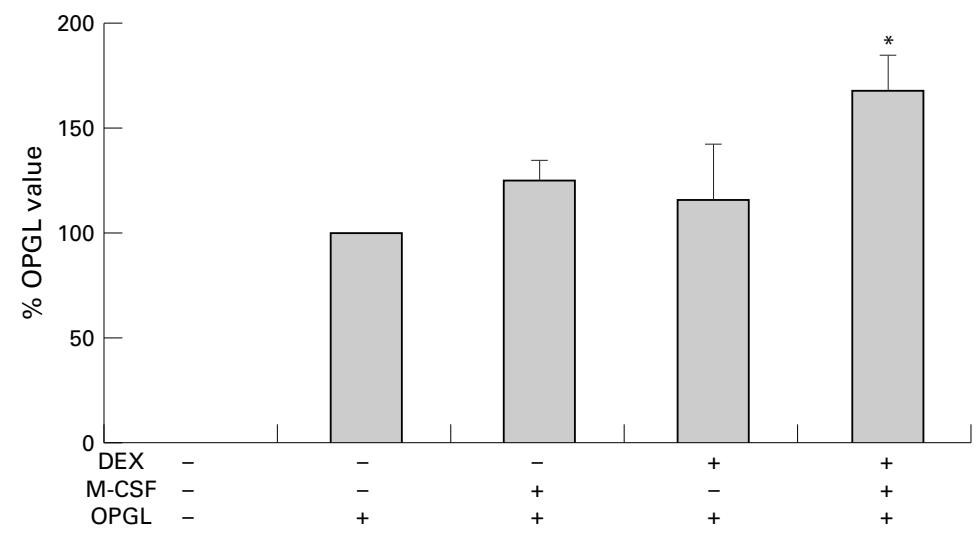

Figure 2 The extent of lacunar resorption on 14 day cultures of arthroplasty macrophages in the presence of: $10^{-8} M$ dexamethasone (DEX) and/or $25 \mathrm{ng} / \mathrm{ml} M-C S F$ and/or 30 $\mathrm{ng} / \mathrm{ml}$ OPGL. Results represent pit numbers expressed as percentage of values obtained in cultures treated with OPGL alone. (Bars represent mean (SD)). ${ }^{*} p<0.05$ as compared with cultures containing OPGL alone.

Table 1 Number of lacunar resorption pits formed on dentine slices after 1, 4, 7, 11 and 14 day incubation with added OPGL of arthroplasty macrophage both in the presence and absence of $M-C S F$ and dexamethasone (DEX). The mean number of resorption pits is shown $(n=3)$

\begin{tabular}{lllllr}
\hline & \multicolumn{7}{l}{ Incubation time (day) } \\
\cline { 2 - 6 } & 1 & 4 & \multicolumn{1}{c}{7} & \multicolumn{1}{c}{11} \\
\hline OPGL & 0 & 2.5 & 5.5 & 10.5 & 9.7 \\
OPGL+M-CSF & 0 & 2 & 7 & 5.7 & 12.7 \\
OPGL+M-CSF+DEX & 0 & 8 & 11 & 11 & 15.3 \\
\hline
\end{tabular}

VNR, and did not show evidence of lacunar resorption. Arthroplasty macrophage cultures, incubated for four days in the presence of OPGL alone, contained a few $\mathrm{TRAP}^{+}$and $\mathrm{VNR}^{+}$mononuclear and multinucleated cells on the coverslips; correspondingly, a few small lacunar resorption pits (mean $=2.5$ pits per dentine slice) were found on the dentine slices. After 7 and 11 days of incubation in the presence of OPGL alone, many $\mathrm{TRAP}^{+}$and $\mathrm{VNR}^{+}$mononuclear and multinucleated cells were observed on coverslips, and numerous lacunar resorption pits were found on dentine slices. The number of both $\mathrm{TRAP}^{+}$and $\mathrm{VNR}^{+}$ cells and resorption pits increased with time of incubation and reached a plateau at 11 days

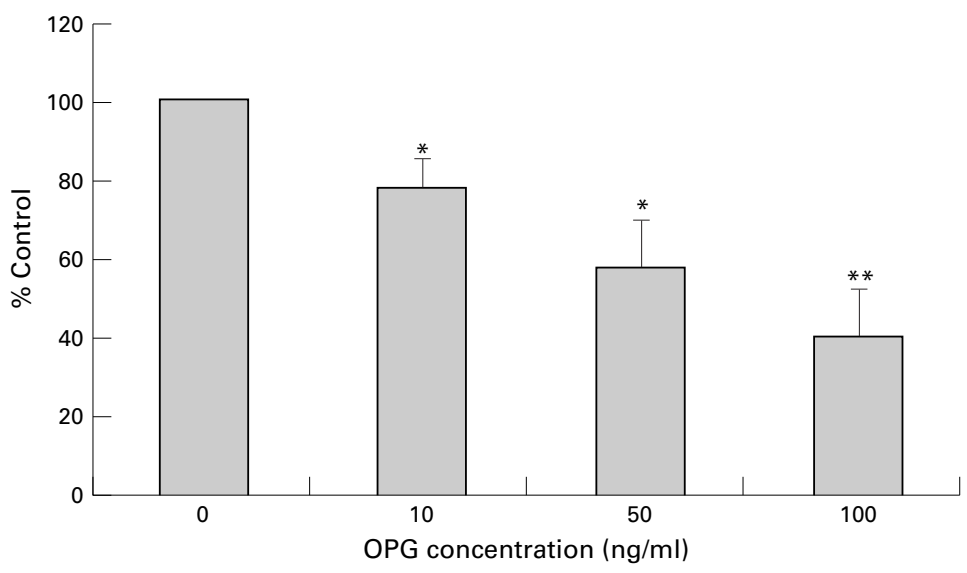

Figure 3 Inhibition of lacunar resorption in arthroplasty macrophage-UMR106 cell cocultures in response to various concentrations of OPG after 14 days incubation. Results. represent pit numbers expressed as percentage of values obtained in control cultures (that is, cultures with no added OPG). (Bars represent mean (SD)). ${ }^{\star} p<0.05,{ }^{\star *} p<0.001$ as compared with control cultures - that is, in the absence of OPG. incubation (table 1). Arthroplasty macrophage cultures, incubated in the presence of OPGL and $\mathrm{M}-\mathrm{CSF}$ and/or dexamethasone, showed a similar pattern of osteoclast differentiation. In these condition, a few $\mathrm{TRAP}^{+}$and $\mathrm{VNR}^{+}$cells and resorption pits were found after four days incubation and numerous large lacunar resorption pits were seen after incubation for 14 days, both in the presence and absence of dexamethasone (table 1).

\section{OPG STUDIES}

Arthroplasty macrophage-osteoclast differentiation in coculture with UMR106 cells

Arthroplasty macrophage-osteoclast differentiation was seen in cocultures of arthroplasty derived macrophages and UMR106 cells. ${ }^{14}$ In all cases, 24 hour cocultures of arthroplasty macrophages and UMR106 cells on glass coverslips in the presence of $1,25(\mathrm{OH})_{2} \mathrm{D}_{3}$ and dexamethasone, were largely positive for the macrophage marker, CD14, and almost entirely negative for the osteoclast markers, TRAP and VNR. In one case, a few isolated $\mathrm{TRAP}^{+}$and $\mathrm{VNR}^{+}$multinucleated cells were seen in 24 hour cultures on coverslips and single resorption pits were seen in the corresponding cultures on dentine slices. This was presumably because of the presence of osteoclasts in the cell suspension isolated from the arthroplasty membrane. In all cases studied, no pits were formed in the absence of UMR106 cells after 24 hour incubation.

After seven days incubation, cocultures of arthroplasty macrophages and UMR106 cells, incubated in the presence of $1,25(\mathrm{OH})_{2} \mathrm{D}_{3}$ and dexamethasone on coverslips, contained numerous $\mathrm{TRAP}^{+}$and $\mathrm{VNR}^{+}$mononuclear and multinucleated cells. In 14 day cocultures of arthroplasty macrophage and UMR106 cells, incubated in the presence of $1,25(\mathrm{OH})_{2} \mathrm{D}_{3}$ and dexamethasone, extensive lacunar pit formation was evident on all dentine slices.

\section{OPG inhibition of arthroplasty}

macrophage-osteoclast differentiation in coculture with UMR106 cells

The addition of OPG to cocultures of arthroplasty macrophages and UMR106 cells, incubated in the presence of $1,25(\mathrm{OH})_{2} \mathrm{D}_{3}$ and dexamethasone, resulted in a dose dependent inhibition of macrophage-osteoclast differentiation and lacunar resorption (fig 3). In seven day cultures on coverslips, the number of $\mathrm{TRAP}^{+}$and $\mathrm{VNR}^{+}$mononuclear and multinucleated cells was decreased. In 14 day cocultures of arthroplasty macrophages and UMR106 cells on dentine slices, the number of lacunar resorption pits formed was also inhibited dose dependently. Relative to untreated controls, the addition of 10,50 , and $100 \mathrm{ng} / \mathrm{ml}$ of OPG resulted in inhibition of pit formation by $23 \%(\mathrm{p}=0.021), 41 \%(\mathrm{p}=0.014)$ and $57 \%$ $(\mathrm{p}=0.004)$, respectively.

\section{Discussion}

Wear particles derived from implant biomaterials induce a pronounced foreign body macrophage response in both the pseudocapsule and pseudomembrane surrounding arthroplasty 
components. ${ }^{28} 29$ The clinical severity and rapidly of onset of aseptic loosening can be correlated with both the amount of wear particle deposition and the extent of the macrophage response in these periprosthetic tissue. ${ }^{30-32}$ In this study we have shown that the capacity of arthroplasty macrophages to differentiate into osteoclasts is OPGL dependent and that this process is inhibited by OPG in a dose dependent fashion.

Our results show that the inflammatory foreign body macrophage infiltrate in periprosthetic tissues, surrounding loose arthroplasty components, contains mononuclear osteoclast precursors and that these cells express the phenotypic characteristics of macrophages and not osteoclasts. Post-mitotic osteoclast precursors of marrow origin have been shown to lose and to acquire macrophage and osteoclast markers respectively, in the process of osteoclast differentiation..$^{33}$ This is paralleled by changes in the cytochemical and functional phenotype that occur in our culture system where isolated arthroplasty derived cells exhibit macrophage and not osteoclast characteristics; becoming $\mathrm{TRAP}^{+}$and $\mathrm{VNR}^{+}$and acquiring the ability to carry out extensive lacunar resorption after OPGL administration or when cocultured with osteoblasts.

OPGL is a membrane expressed ligand first identified on T cells. It is a novel member of the TNF ligand superfamily. ${ }^{34-36}$ The same ligand has been identified on osteoblasts and bone marrow stromal cells and with M-CSF has been shown to induce the differentiation of osteoclasts from circulating and marrow precursors. ${ }^{16}{ }^{17} 37{ }^{38}$ It has been known for some time that in monocyte and macrophage populations there are mononuclear osteoclast precursors that, when cultured with osteoblastic cells, in the presence of M-CSF and calciotropic hormones such as $1,25(\mathrm{OH})_{2} \mathrm{D}_{3}$, are capable of differentiating into osteoclasts in vitro. $^{13}{ }^{15}$ Osteoclast precursors isolated from periprosthetic tissues form a unique category of such mononuclear phagocyte precursors in that they do not require the addition of exogenous M-CSF for osteoclast formation. ${ }^{14}$ In this study, we have shown that OPGL can substitute for osteoblasts and $1,25(\mathrm{OH})_{2} \mathrm{D}_{3}$ in promoting macrophage-osteoclast differentiation and that indeed OPGL is the sole exogenous humoral factor that is required for this to occur. These findings indicate that the mononuclear phagocyte osteoclast precursors in the macrophage infiltrate of the arthroplasty membrane must express a receptor for OPGL. Two receptors for OPGL have recently been identified: the first is soluble decoy receptorthat is, OPG - and the other is a membrane bound receptor, known as OPGL-R. OPGL-R protein expression has been reported on activated T lymphocytes, dendritic cells, osteoclast precursors and mature osteoclasts. ${ }^{17} 35363940$ Haynes et al have recently shown that the expression of mRNA for OPGL and OPGL-R is stimulated by human mononuclear cells exposed to orthopaedic biomaterials such as titanium. ${ }^{41}$
OPG inhibition of arthroplasty macrophageosteoclast differentiation accords with a central role for OPGL in inducing osteoclast formation and bone resorption in aseptic loosening. OPG is a novel member of the TNF receptor superfamily, which, in contrast with other TNF receptors, lacks a transmembrane domain. ${ }^{18-20}$ This indicates that OPG is secreted as a soluble factor that may act to modulate osteoclast formation in an autocrine or paracrine fashion. OPG is produced by human and mouse osteoblasts $^{18} 42$ and has been shown to bind to stromal cells that support osteoclast differentiation. Both in vivo and in vitro studies, have shown that OPG has a major effect on bone resorption. Transgenic mice expressing OPG cDNA have high circulating levels of OPG and are osteopetrotic, exhibiting decreased number of osteoclasts in bone, whereas OPG deficient mice are osteoporotic. ${ }^{18}{ }^{43}$ As we have shown that OPGL and OPG profoundly influence osteoclast formation from mononuclear phagocyte osteoclast precursors isolated directly from the arthroplasty pseudomembrane, these factors are likely to play a major part in controlling the osteolysis of aseptic loosening. Osteoclast formation in periprosthetic tissues can be viewed as a balance between the production of OPGL and OPG, its soluble decoy receptor, by stromal cells and inflammatory cells at the bone and implant interface.

Of interest in regard to osteoclast formation and bone resorption in aseptic loosening is the role of various cellular and humoral factors on OPG and OPGL production. Inflammatory cells such as $T$ cells are present in the arthroplasty membrane and may influence osteoclast differentiation and periprosthetic osteolysis by modulating OPGL expression and OPG production. ${ }^{17}{ }^{34-36}{ }^{44}$ Of the cytokines known to be abundant in periprosthetic tissues in aseptic loosening, interleukin 1 and $\mathrm{TNF}$, but not interleukin 6 , have been shown to increase OPG mRNA expression by osteoblasts. ${ }^{45}{ }^{46}$ Thus, interleukin 1 and TNF, which are both known to stimulate the bone resorbing activity of osteoclasts, would appear to act conversely to downregulate osteoclast formation. $\mathrm{PGE}_{2}$, which is also abundant in periprosthetic tissues, has been shown to increase OPGL production and to decrease OPG release, thus stimulating osteoclast formation and bone resorption. ${ }^{47-49}$ Macrophages are also capable of producing $1,25(\mathrm{OH})_{2} \mathrm{D}_{3}$, the active metabolite of vitamin $\mathrm{D}_{3} .{ }^{50}$ This has been shown to increase the ratio of OPGL to OPG production and thus osteoclast formation. ${ }^{48}$ In the heavy foreign body macrophage infiltrate in periprosthetic tissues, increased local production of $1,25(\mathrm{OH})_{2} \mathrm{D}_{3}$ by these cells may be another mechanism whereby osteoclast formation and osteolysis is increased.

The authors wish to thank Dr D Lacey, Amgen, CA for providing the OPG and OPGL.

Funding: this research was funded by the Wellcome Trust.

1 Bullough PG, DiCarlo EF, Hansraj KK, Neves MC. Pathologic studies of total joint replacement. Orthop Clin North Am 1988;19:611-25. 
2 Lennox DW, Schofield BW, McDonald DF, Riles LH. A histologic comparison of aseptic loosening of cemented,
press-fit and biologic ingrowth prostheses. Clin Orthop press-fit and biologi

3 Revell PA. Tissue reactions to joint prostheses and the products of wear and corrosion. In: Berry C, ed. Current trends in pathology. Berlin: Springer-Verlag: 1982:73-101.

4 Harris WH. Osteolysis and particle disease in hip replacements (a review). Acta Orthop Scand 1994;65:113-23.

5 Harris WH. The problem is osteolysis. Clin Orthop 1995;311:46-53

6 Goodman SB, Chin RC. Prostaglandin E2 levels in the membrane surrounding bulk and particulate polymethylmethacrylate in the rabbit tibia: a preliminary study. Clin Orthop 1990;257:305-9.

7 Goodman SB, Chris RC, Chiou SS, Schurman DJ, Woolson ST, Masada MP. A clinical-pathological-biochemical study of the membrane surrounding loosened and non loosened of the membrane surrounding loosened and non loos

8 Murray DW, and Rushton N. Macrophages stimulate bone resorption when they phagocytose particles. J Bone Joint resorption when they phago
Surg Br 1990;72-B:988-92.

9 Jiranek WA, Machado M, Jasty M, Jervevar D Wolfe HJ, Goldring SR, et al. Production of cytokines around loosened cemented acetabular components. J Bone Joint Surg Am 1993;75-A:863-79.

10 Kim KJ, Rubash HE, Wilson SC, D'Antonio JA, McClain EJ. A histologic and biochemical comparison of the interface tissues in cementless and cemented hip prostheses. Clin Orthop 1993;287:142-52.

11 Quinn JM, Joyner C, Triffitt JT, Athanasou NA. PMMAinduced inflammatory macrophages resorb bone. J Bone Joint Surg Br 1992;74-B:652-8.

12 Quinn JMW, Sabokbar A, NA Athanasou. Cells of the mononuclear phagocyte series differentiate into osteoclastic lacunar bone resorbing cells. J Pathol 1996;179:106-11.

13 Udagawa N, Takahashi N, Akatsu T, Tanaka H, Sasaki T, Nishihara T, et al. Origin of osteoclasts: Mature monocytes and macrophages are capable of differentiating into osteoclasts under a suitable microenvironment prepared by bone clasts under a suitable microenvironment prepared by bone marrow-derived

14 Sabokbar A, Fujikawa Y, Neale S, Murray DW, Athanasou NA. Human arthroplasty macrophages differentiate into osteoclastic bone resorbing cells. Ann Rheum Dis 1997;56: 414-20.

15 Fujikawa Y, Quinn JMW, Sabokbar AS, McGee JOD, Athanasou NA. The human mononuclear osteoclast precursor circulates in the monocyte fraction. Endocrinology 1996; 137:4058-60.

16 Yasuda H, Shima N, Nakagawa N, Yamaguchi K, Kinosaki M, Mochizuki S-I, et al. Osteoclast differentiation factor is a ligand for osteoprotegerin/osteoclastogenesis-inhibitory factor and identical to TRANCE-RANKL. Proc Natl Acad Sci USA 1998;95:3597-602.

17 Lacey DL, Timms E, Tan H-L, Kelley MJ, Dunstan CR, Burgess T, et al. Osteoprotegerin ligand is a cytokine that regulates osteoclast differentiation and activation. Cell regulates osteoc

18 Simonet WS, Lacey DL, Dunstan CR, Kelley M, Chang MS, Lüthy R, et al. Osteoprotegerin: a novel secreted protein involved in the regulation of bone density. Cell 1998;89:309-19.

19 Tsuda E, Goto M, Mochizuki S-I, Yano K, Kobayashi F, Morinaga $\mathrm{T}$, et al. Isolation of a novel cytokine from human fibroblasts that specifically inhibits osteoclastogenesis. Biochem Biophys Res Commun 1997;234:137-42.

20 Yasuda H, Shima N, Nakagawa N, Mochizuki S-I, Yano K, Fujise N, et al. Identity of osteoclastogenesis inhibitory factor (OCIF) and osteoprotegerin (OPG): a mechanism by which OPG/OCIF inhibits osteoclastogenesis in vitro. Endocrinology 1998;139:1329-37.

21 Partridge N, Alcorn D, Michelangeli V, Kemp E, Ryan G, Martin TJ. Functional properties of hormonal responsive cultured normal and malignant rat osteoblastic cells. Endocrinology 1981;108:213-19.

22 Andersson G, Ek-Rylander B, Minkin C. Acid phosphatases. In: Rifkin BR, Gay CV, eds. Biology and physiology phatases. In: Rifkin BR, Gay CV, eds. Biology and physiolo

23 Gatter KC, Falini B, Mason DY. The use of monoclonal antibodies in histological diagnosis, In: Anthony PP, Mac Sween RNM, eds. Recent advances in histopathology, no12. Edinburgh: Churchill Livingstone, 1984:35-67.

24 Horton MA, Lewis D, McNulty K, Pringle JAS, Chambers TJ. Monoclonal antibodies to osteoclastomas (giant cell bone tumours): definition of osteoclast specific cellular antigens. Cancer Res 1985;45:5663-9.

25 Athanasou NA, Quinn J. Immunophenotypic differences between osteoclasts and macrophage polykaryons: immunohistological distinction and implications for osteoclast ontogeny and function. J Clin Pathol 1990;43:997-1004.

26 Schlossman SF, Boumsell L, Gilks W, Harlan JM, Kishimoto T, Morimoto C, et al. Leucocyte typing V: white cell differentiation antigens. Oxford: Oxford University Press, 1995.

27 Boyde A, Ali NN, Jones SJ. Resorption of dentine by isolated osteoclasts in vitro. Br Dent J 1984;156:216-20.

28 Amstutz HC, Campbell P, Kossovsky N, Clarke IC. Mechanisms and clinical significance of wear debris-induced osteolysis. Clin Orthop 1992;276:7-18.
29 Horowitz SM, Purdon MA. Mechanisms of cellular recruitment in aseptic loosening of prosthetic joint implants. Calcif Tissue Int 1995:57:301-5.

30 Malcolm AJ. The pathology of long-standing cemented total hip replacement in Charnley's cases. J Bone Joint Surg Br 1988;70-B:153-6.

31 Santavirta S, Hoikka V, Eskola A, Kontinnen Y, Paavilainen T, Tallroth V. Aggressive granulomatous lesions in cementless tota

32 Santavirta S, Konttinen TY, Bergroth V, Eskola A, Tallroth $\mathrm{K}$, Lindholm TS. Aggressive granulomatous lesions associated with hip arthroplasty: immunopathological studies. J Bone Joint Surg Am 1990;72-A:252-8.

33 Quinn JMW, McGee JO'D, Athanasou NA. Cellular and hormonal factors influencing monocyte differentiation to osteoclastic bone resorbing cells. Endocrinology 1994;134: 2416-23.

34 Wong BR, Rho J, Arron J, Robinson E, Orlinick J, Chao M, et al. TRANCE is a novel ligand of the tumor necrosis factor receptor family that activates c-Jun N-terminal kinase in tor receptor family that activates c-Jun N-ter

35 Wong BR, Josien R, Lee SY, Sauter B, Li H-L, Stainman $\mathrm{RM}$, et al. TRANCE (tumor necrosis factor (TNF)-related activation-induced cytokine), a new TNF family member predominantly expressed in $\mathrm{T}$ cells, is a dendritic cell-specific survival factor. J Exp Med 1997;186:2075-80.

36 Anderson DM, Maraskovsky E, Billingsley WL, Dougall WC, Tometsko ME, Roux ER, et al. A homologue of the TNF receptor and its ligand enhance T-cell growth and dendritic-cell function. Nature 1997;390:175-9.

37 Quinn JMW, Elliott J, Gillespie MT, Martin TJ. A combination of osteoclast differentiation factor and macrophagecolony stimulating factor is sufficient for both human and mouse osteoclast formation in vitro. Endocrinology 1998; 139:4424-7

38 Matsuzaki K, Udagawa N, Takahashi N, Yamaguchi K, Yasuda $\mathrm{H}$, Shima $\mathrm{N}$, et al. Osteoclast differentiation factor (ODF) induces osteoclast-like cell formation in human peripheral blood mononuclear cell cultures. Biochem Biophys Res Commun 1998;246:199-204.

39 Fuller K, Wong B, Fox S, Choi Y, Chambers TJ. TRANCE is necessary and sufficient for osteoblast-mediated activation of bone resorption in osteoclasts. J Exp Med 1998;188:997-1001.

40 Nakagawa N, Kinosaki M, Yamaguchi K, Shima N, Yasuda $\mathrm{H}$, Yano $\mathrm{K}$, et al. RANK is the essential signaling receptor for osteoclast differentiation factor in osteoclastogenesis. Biochem Biophys Res Commun 1998;253:395-400.

41 Haynes DR, Potter AE, Atkins GJ, Findlay DM, Crotti T, Howie DW, et al. Metal particles stimulate expression of regulators of osteoclast development including osteoclast differentiation factor (RANKL/TRANCE), osteoprotegerin and M-CSF. 45th Annual Meeting of Orthopaedic Research Society, Anaheim, California. Trans Orthop Res Soc $1999 ; 24: 244$

42 Vidal ONA, Brändström $\mathrm{H}$, Jonsson $\mathrm{KB}$, Ohlsson C. Osteoprotegerin mRNA is expressed in primary human osteoblast-like cells: down-regulation by glucocorticoids. J Endocrinol 1998;159:191-5.

43 Mizuno A, Amizuka N, Irie K, Murakami A, Fujise N, Kanno $\mathrm{T}$, et al. Severe osteoporosis in mice lacking osteoclastogenesis inhibitory factor/osteoprotegerin. Biochem Biophys Res Commun 1998;247:610-15.

44 Yun TJ, Chaudhary PM, Shu GL, Frazer JK, Ewings MK, Schwartz SM, et al. OPG/FDCR-1, a TNF receptor family member, is expressed in lymphoid cells and is up-regulated by ligating CD40. J Immunol 1998;161:6113-21.

45 Brändström $\mathrm{H}$, Jonsson $\mathrm{KB}$, Vidal $\mathrm{O}$, Ljunghall $\mathrm{S}$, Ohlsson $C$, Ljunggren Ö. Tumor necrosis factor- $\alpha$ and $-\beta$ upregulate the levels of osteoprotegerin mRNA in human osteosarcoma MG-63 cells. Biochem Biophys Res Commun 1998;248:454-7.

46 Vidal ONA, Sjögren K, Eriksson BI, Ljurggren Ö, Ohlsson C. Osteoprotegerin mRNA is increased by Interleukin- $1 \alpha$ in the human osteosarcoma cell line MG-63 and in human osteoblast-like cells. Biochem Biophys Res Commun 1998; 248:696-700

47 Brändström $\mathrm{H}$, Jonsson $\mathrm{KB}$, Ohlsson $\mathrm{C}$, Vidal $\mathrm{O}$, Ljunghall $\mathrm{S}$, Ljunggren Ö. Regulation of osteoprotegerin mRNA levels by prostaglandin $\mathrm{E}_{2}$ in human bone marrow stroma cells. Biochem Biophys Res Commun 1998;247:338-41.

48 Tukii K, Shima N, Mochizuki S-I, Yamaguchi K, Kinosaki $\mathrm{M}$, Yano $\mathrm{K}$, et al. Osteoclast differentiation factor mediates an essential signal for bone resorption induced by $1 \alpha, 25$ dihydroxyvitamin $\mathrm{D}_{3}$, prostaglandin $\mathrm{E}_{2}$, or parathyroid hormone in the microenvironment of bone. Biochem Biophys Res Commun 1998;246:337-41.

49 Horwood NJ, Elliott J, Martin TJ, Gillespie MT. Osteotropic agents regulate the expression of osteoclast differentiation factor and osteoprotegerin in osteoblastic stromal cells. Endocrinology 1998;139:4743-6.

50 Hayes ME, Denton J, Freemont AJ, Mawer EB. Synthesis of active metabolite of vitamin $\mathrm{D}, 1,25(\mathrm{OH})_{2} \mathrm{D}_{3}$, by synovial fluid macrophages in arthritic disease. Ann Rheum Dis 1989;48:723-9. 